\title{
Static and dynamic evaluation of respiratory muscle strength in asthmatic children and adolescents
}

\author{
Jean Aretakis Cordeiro 1 \\ iD https://orcid.org/0000-0002-7639-1250 \\ Caroline Palácio Silva 2 \\ iD https://orcid.org/0000-0002-4485-2382 \\ Murillo Carlos Amorim Britto 3 \\ https://orcid.org/0000-0002-1566-6310 \\ Lívia Barboza Andrade 4 \\ https://orcid.org/0000-0002-5647-1835
}

\footnotetext{
1 Faculdade Pernambucana de Saúde. Recife, PE, Brasil.
}

2-4 Instituto de Medicina Integral Professor Fernando Figueira. Rua dos Coelhos, 300. Recife, PE, Brasil. CEP: 50.070-902. E-mail: ftliviabandrade@gmail.com

\begin{abstract}
Objectives: to evaluate static and dynamic respiratory muscle strength in children and adolescents with asthma.

Methods: cross-sectional study, involving 80 children and adolescents, 40 with asthma and 40 healthy controls. Biological and clinical characteristics were analyzed. The analysis of the dynamic inspiratory muscle strength was obtained using the KH5 device of the $P O W E R b r e a t h e \AA$ line, while the static evaluation was performed using an analog manovacuometer.

Results: the mean obtained from the S-Index was higher in the control group compared to asthmatics $(p=0.026)$. There was no statistical difference between MIP values for asthmatics and predicted values $(p=0.056)$. The MEP results showed a significant difference between the mean of the cases and the predicted values $(p=0.000)$. There was a positive correlation between height and S-Index ( $p=0.002$ and $r=0.438)$.

Conclusion: the present study demonstrated that the static inspiratory muscle strength (PImáx) of children and adolescents with asthma in comparison with the values predicted in the literature does not differ, however, when submitted to dynamic assessment (S-Index), it presents higher values in healthy controls. In addition, the S-Index showed a positive correlation with the child's height.
\end{abstract}

Key words Asthma, Respiratory muscles, Child, Respiratory function tests, Muscle strength 


\section{Introduction}

Respiratory diseases are responsible for a large portionof morbimortality rates within children, in both acute and chronic conditions. ${ }^{1}$ In regards of chronic diseases, specially asthma, it can affect children health and lead to an adaptation and modification of life habits, causing a profound impact in quality of life of both children and their family. ${ }^{2}$ Considered the most common non-communicable disease in childhood and adolescence, asthma is a worldwide health problem which affects around 300 million people. In Brazil, it is estimated around 20 million people with asthma, resulting in high rates of hospital internment and elevated health care costs. ${ }^{3-5}$

By definition, it is an inflammatory disease of lower respiratory tract, characterized by an exacerbated increase of bronchial responsiveness due to various stimuli and variable obstruction of respiratory flux. ${ }^{4}$ It is manifested with recurrent episodes of hissing, cough, dyspnea and chest constriction. ${ }^{4}$ Such functional alterations negatively impact the quality of life of these patients, limiting their daily activities and practice of recreational exercises. ${ }^{2}$

The obstruction of respiratory flux in patients with asthma induces a progressive imprisonment of air in alveolar units. ${ }^{5-7}$ The pulmonary hyperinflation generated compromises respiratory musculature, resulting in an increase of respiratory labor and higher energy expenditure to surpass the resistance imposed by the respiratory tract,5-7 Among the mechanic disadvantages caused by this respiratory condition, the main factors include the reduction of diaphragm length and accessory inspiratory muscles, leading them to function under the length tension curve. Besides, hyperinflation yet provokes increased elevation of ribs, setting horizontally their position, causing the lowering of hemidiaphragms, decreasing the zone of apposition with consequent limitation of chest expansibility and reduction of total lung capacity (TLC). 8,9

Added to mechanic disadvantages, the usage of corticosteroids in long term, even in small doses, may contribute to the increase of respiratory muscle weakness. ${ }^{10,11}$ Among its adverse effects, the reduction of protein synthesis and increase of its degeneration contribute to the onset of muscular atrophy. 12 This status of respiratory muscle deficiency contributes to higher risk of muscle fatigue, ineffective expectoration and intolerance to exercises due to the presence of dyspnea when practicing various physical activities. 13

Thus, the quantification of muscular strength in asthmatic patients is of elementary importance, in an attempt of permitting adequate evaluation and treatment. The most used way in clinical practice to evaluate respiratory muscle strength is maximum inspiratory pressure (MIP) which consists in measuring the pressure generated by inspiratory muscles in upper respiratory tract by means of a mask or mouthpiece during a voluntary maximum inspiration out of the residual volume or the residual functional capacity by means of a manovacuometer. ${ }^{14,15} \mathrm{As}$ it is a static measurement, MIP evaluates respiratory muscle strength only in the isometric way, not being possible to evaluate strength during inspiration. 16

New devices such as POWERbreathe ${ }^{\circledR}$, England, UK were developed with the purpose of measuring the dynamic strength of inspiratory muscles. Unlike MIP, the dynamic assessment measures strength in full amplitude of chest movement, making it possible to be visualized and registered by means of graphical analysis, which permits higher precision of results. 17 This device is capable of registering the variation of flux during inspiration, calculating inspiratory muscle strength. The peak value or global inspiratory muscle strength is called S-Index, being possible, thus, to indicate or suggest the presence of muscle weakness. 17

In the view of the above, and considering the absence of researches in this field, the objective of this study was to analyze static and dynamic respiratory muscle strength in children and adolescents with asthma.

\section{Methods}

Cross-sectional study with comparative group, executed in the outpatient care center of Pediatric Pulmonology of Institute of Integrative Medicine Professor Fernando Figueira (IMIP - Portuguese acronym), located in Recife, State of PernambucoBrazil. IMIP is an institution of care, teaching and research, reference in childhood respiratory diseases, attending the population exclusively through the Unified Health System (SUS - Portuguese acronym). The study was executed within the timespan from August 2018 to April 2019. Children and adolescents with ages ranging from 6 to 18 years old were enrolled, with clinical diagnosis of persistent asthma. 18 Patients with other associated pulmonary diseases or those unable to execute adequately the maneuver of evaluation were excluded from the study.

The enrollment of participants occurred by means of active search in pulmonology service, in which those eligible were invited to participate, sign the consent form and the assentment form when 
pertinent. In front of the gap which exists in reference values for S-Index (dynamic assessment of muscle strength) in the study population, a control group was created with children and adolescents without asthma or any associated pulmonary disease, matched by biological characteristics of sex, age, weight and height with the same number of participants. The mensuration followed the same technique standard used in the group of asthmatic children and participants were brought from a public school in the municipality of Olinda-PE.

The sample was a convenience model executed consecutively in the study period. Data collection started with information referring to the total daily dose of inhaled corticoids ministered in micrograms (mcg), through the scale suggested by Global Initiative for Asthma (GINA).18 Prior to that, the participants were asked by the level of physical activity, by means of a score adapted from the Habitual level physical activity - HLPA of Santuz et al. 19 questionnaire. The sample was classified in relation to the body mass index (BMI), according to the values obtained from the online calculator available in the Virtual Heath Library website, specific form children and adolescents, based on the respective percentiles. 20 The environmental control was analyzed, and the participants/guardians were asked about exposure dust, mold and pets. Those in contact with at least one of these items were classified as inadequate environmental control; besides, smoke exposure was also evaluated.

In order to evaluate maximum respiratory pressure (MIP and MEP), an analog Indumed ${ }^{\circledR}$ manovacuometer was used, and the mensuration followed the standards of American Thoracic Society (ATS, 2002). 21 Three interspersed measurements were taken, with a minute of interval. Patients received verbal incentive ad visual feedback. The highest value obtained was considered in the analysis and compared to other values proposed by Lanza et al.22 equation.

After evaluation of static muscle strength, an interval of 15 minutes was given to the patients, so that they can rest their musculature, and then dynamic assessment was continued by means of SIndex, avoiding the occurring of interference in the measured values. For the S-Index, the position of the patient in chair and of the mouthpiece was the same used in static evaluation. However, in this analysis, an electronic device of linear charge (KH5 from POWERbreathe ${ }^{\circledR}$ line) was used. The patients were oriented to expire until the residual volume is reached, and after this, to execute a maximum inspiration, being executed 10 maneuvers, without inter- vals among them, and the higher value was considered for analysis since the curve was acceptable and reproducible. The measurements were considered acceptable, in case of being maintained without air leaking for at least 2 to 3 seconds and if 2 readings were made with a differentiation maximum of $20 \%$, following the orientations of the manufacturer. As well as in the static evaluation, patients also received verbal incentive and visual feedback. 16,17

For the statistical analysis STATA program, version 8 was used. The measured variables were exposed in tables of distribution frequency for categorical variables, calculating the means and their respective standard deviations. For distribution of variables, Shapiro-Wilk test was used. In the analysis between asthmatics and comparative group, the t-student test was applied, and for the analysis of quantitative variables, the chi-square test. Spearman's correlation was used between biological variables and static and dynamic muscle strength. Level of significance $p>0.05$ was adopted.

The study was approved by the Committee for Ethics in Research on Human Beings of the institution, under the CAAE number 84171618.3. 0000.5201 .

\section{Results}

40 asthmatic children and adolescents were evaluated, as shown in Figure1. The comparative group was also composed by 40 non-asthmatic children and adolescents, totaling 80 participants. The mean of age, weight and height in both groups were similar (Table 1).

It was observed that $52.2 \%$ of the sample with asthmatic children and adolescents were males. In regards of clinical characteristics, $35.0 \%$ presented BMI higher than recommended, being $20 \%$ classified as overweight and $15 \%$ as obese, however, the highest percentage (57.5\%) as eutrophic. In relation to income, $22.5 \%$ of the population in the analysis had total family income lower than a minimum wage, $37.5 \%$ equal to a minimum wage, and $40 \%$ higher than a minimum wage (Table 2). Yet in the descriptive analysis, in regards to exposure to factors which triggers asthma, $75 \%$ did not obtain adequate environment. Other characteristics of these patients, including control of disease, inhaled corticoid and level of physical activity are shown in Table 2.

The analysis of behavior of means from values obtained in dynamic muscle strength assessment (SIndex) and static values (MIP and MEP) are shown in Table 3. It was noted that the mean obtained in SIndex was higher in control group compared to asth- 


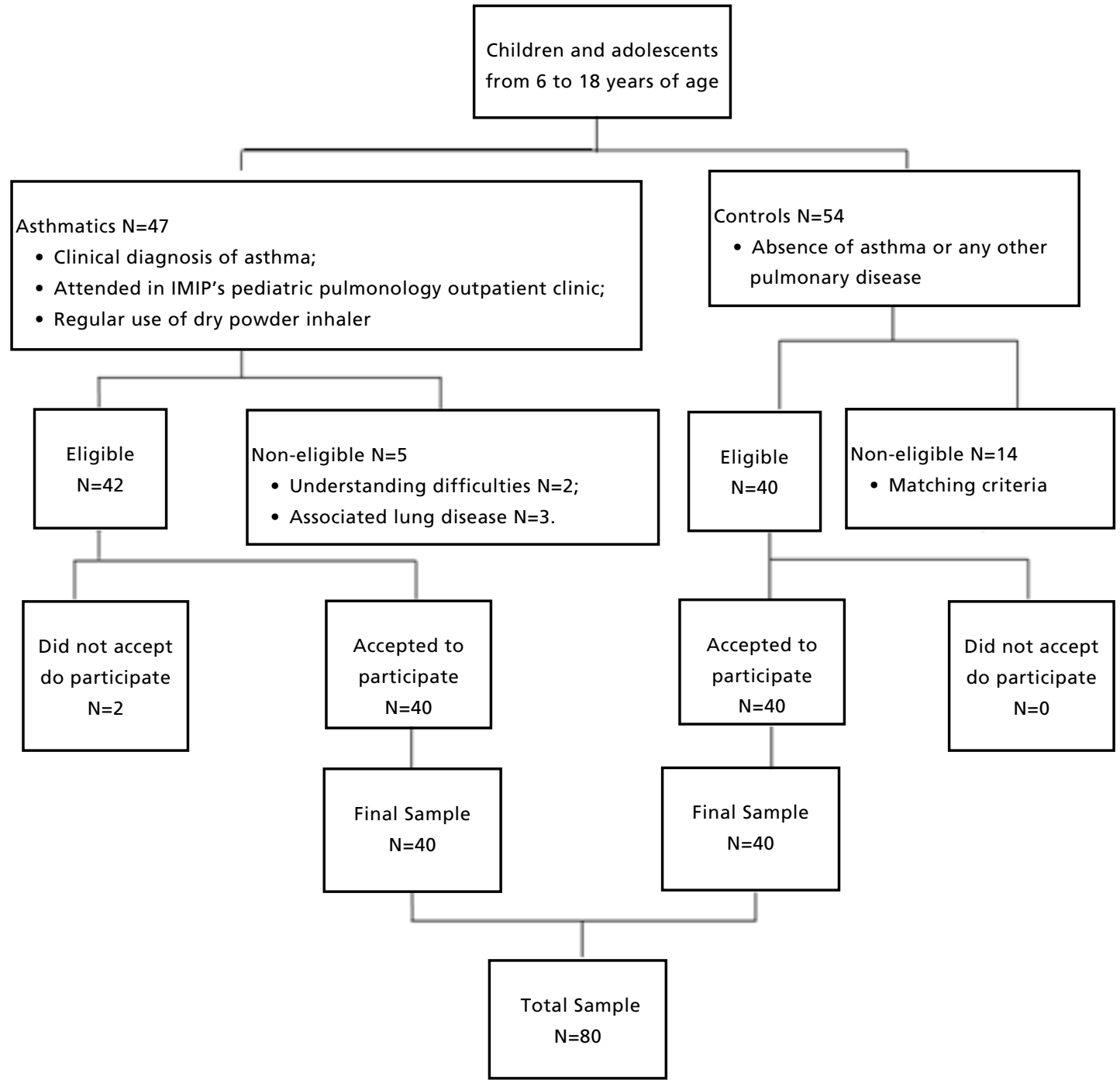

matic group. In relation to the evaluation of static muscle strength, the MIP values of asthmatic group were lower in relation to the expected predicted values, however, without significant difference. MEP showed significant difference in asthmatics compared to predicted values (Table 3 ).

Regarding the correlation with biological variables and the MIP and MEP, with the S-Index (Table 4 ), it was observed a positive correlation between height variables and S-Index, which points to a directly proportional relation, that is, the higher the height, the higher the S-Index of studied patients. There was no significant correlation between the other variables and S-Index.

\section{Discussion}

In our study, the dynamic analysis of inspiratory muscles evidenced superiority in healthy children compared to asthmatic children. The behavior of static respiratory muscle strength compared to the standard predicted values demonstrated difference in maximum expiratory pressure. When compared to static and dynamic strength only in the group of asthmatic children, it was observed that the MIP was higher than the S-Index. 
Table 1

Characterization of sample according to age and anthropometric measures. Recife, 2019.

\begin{tabular}{|c|c|c|c|}
\hline \multirow[t]{2}{*}{ Characteristics } & Asthmatics $(n=40)$ & Non- asthmatics $(n=40)$ & $p^{*}$ \\
\hline & $\bar{x} \pm D P$ & $\bar{X} \pm D P$ & \\
\hline Age (years) & $14 \pm 3.46$ & $14 \pm 3.46$ & 1.000 \\
\hline Weight (kg) & $52.8 \pm 13.0$ & $55.8 \pm 12.9$ & 0.729 \\
\hline Height (m) & $1.57 \pm 0.12$ & $1.60 \pm 0.11$ & 0.408 \\
\hline
\end{tabular}

* Student's t test.

Table 2

Sociodemographic characteristics of patients with persistent asthma. Recife, 2019.

\begin{tabular}{|c|c|c|}
\hline Socioeconomic variables & $\mathbf{N}$ & $\%$ \\
\hline \multicolumn{3}{|l|}{ Sex } \\
\hline Male & 21 & 52.5 \\
\hline Female & 19 & 47.5 \\
\hline \multicolumn{3}{|c|}{ Family income (minimum wage) } \\
\hline$<1$ & 9 & 22.5 \\
\hline 1 & 15 & 57.5 \\
\hline$>1$ & 16 & 40.0 \\
\hline \multicolumn{3}{|l|}{ BMI } \\
\hline Low for age & 3 & 7.5 \\
\hline Adequate or eutrophic & 23 & 57.5 \\
\hline Overweight & 8 & 20.0 \\
\hline Obesity & 6 & 15.0 \\
\hline \multicolumn{3}{|l|}{ Schooling } \\
\hline Elementary & 30 & 75.0 \\
\hline High school & 8 & 20.0 \\
\hline University & 2 & 5.0 \\
\hline \multicolumn{3}{|l|}{ Smoke } \\
\hline Yes & 2 & 5.0 \\
\hline No & 38 & 95.0 \\
\hline \multicolumn{3}{|l|}{ Environmental control } \\
\hline Yes & 10 & 25.0 \\
\hline No & 30 & 75.0 \\
\hline \multicolumn{3}{|c|}{ Daily dose of inhaled corticoid (mcg) } \\
\hline Low & 20 & 50.0 \\
\hline Medium & 13 & 32.5 \\
\hline High & 7 & 17.5 \\
\hline \multicolumn{3}{|c|}{ Physical activity level - HLPA (N=40) } \\
\hline Sedentary & 11 & 37.5 \\
\hline$<$ or up to $2 \mathrm{hrs} /$ week & 16 & 40.0 \\
\hline$>2 \mathrm{hrs} /$ week & 13 & 32.5 \\
\hline
\end{tabular}

MW= Minimum Wage; $B M I=$ Body Mass Index; HLPA = Habitual level physical activity. Values expressed in absolute and percentage numbers 
Table 3

Comparison of values of respiratory dynamics muscle strength between asthmatics and controls and static strength with predicted values. Recife, 2019.

\begin{tabular}{|c|c|c|c|c|c|}
\hline \multirow[t]{2}{*}{ Characteristics } & \multicolumn{2}{|c|}{ Asthmatics } & \multicolumn{2}{|c|}{ Controls } & \multirow[t]{2}{*}{$p^{*}$} \\
\hline & $\mathrm{N}$ & $\bar{X} \pm D P$ & $\mathrm{~N}$ & $\bar{X} \pm D P$ & \\
\hline \multirow[t]{2}{*}{ S-Index } & 40 & $77.58 \pm 15.21$ & 40 & $83.48 \pm 23.46$ & 0.026 \\
\hline & \multicolumn{2}{|c|}{ Asthmatics } & \multicolumn{2}{|c|}{ Predicted Values } & \\
\hline MIP & 40 & $100 \pm 20.90$ & 40 & $109.46 \pm 10.35$ & 0.056 \\
\hline MEP & 40 & $89 \pm 24$ & 40 & $99.98 \pm 8.86$ & $<0.001$ \\
\hline
\end{tabular}

MIP = Maximum inspiratory pressure; MEP Maximum expiratory pressure; *Student's $t$ test.

Table 4

Correlations between biological variables and static and dynamic muscle strength of asthmatic patients. Recife, 2019.. Recife, 2019.

\begin{tabular}{lcc}
\hline Correlation & $\mathbf{R}$ & $\boldsymbol{p}$ \\
\hline Age x S-Index & -0.063 & 0.682 \\
Weight x S-Index & 0.282 & 0.061 \\
Height x S-Index & 0.438 & $0.002^{*}$ \\
MIPcase x S-Index & -0.003 & 0.982 \\
\hline
\end{tabular}

MIP = Maximum inspiratory pressure; $\mathrm{R}=$ rho; * $p<0.05$. Spearman's Correlation.

The static respiratory muscle strength (MIP) of asthmatic patients, besides having shown itself slightly inferior, didn't diverge significantly from the predicted values for the Brazilian children population. This fact was also observed in the study carried out by Marcelino et al.,11 in which there wasn't statistical difference in MIP between asthmatic children and their controls. This finding can be considered questionable, as asthmatic children suffer with alterations in pulmonary function and ventilation biomechanics, and lower muscle strength values would be expected. This convergence of findings in the two populations can be explained because MIP evaluates respiratory muscle strength in the residual volume or residual functional capacity in an isometric manner, not being possible to observe the strength performance during the entire inspiration. ${ }^{14,15}$

Murphy and Wilson ${ }^{23}$ related the existence of significant differences in the patterns of neural activation of muscles during isometric maneuvers related to dynamic contractions. The device which evaluates inspiratory strength during the entire maneuver (isokinetic), as POWERbreathe ${ }^{\circledR}$, can propose a more reliable evaluation, from the residual volume or residual functional capacity to the maximum pulmonary capacity, when compared to MIP in asthmatic children and adolescents.

Melzer and Souhrada, 24 in a study which aimed to evaluate MIP by means of mensuration of esophageal pressure, observed that it is diminished in asthmatic people. Other studies which evaluated MIP through manovacuometer did not observe alterations in asthmatic patients, accordingly, this instrument might not be sufficiently reliable for the evaluation. 25,26 Once the mensuration technique through esophageal pressure is performed invasively, besides its high cost, the dynamic assessment using POWERbreathe ${ }^{\circledR}$, may be a better alternative for clinical practive. 24

In the dynamic assessment of respiratory muscle strength (S-Index), it was possible to observe inferior values in the asthmatic children group compared to control group matched by age, sex and height. Such results are in line which a variety of biomechanical disadvantages which asthmatic patients can develop, implying in a reduction of respiratory muscle strength. ${ }^{8}$ However, this suggestions are limited, since until the present moment there is no studies which evaluate S-Index in asthmatic patients. 
This study is pioneer in this dynamic analysis of inspiratory muscle strength in children, being not possible, in this way, to compare with prior measurements.

Silva et al. ${ }^{27}$ evaluated the S-Index of 81 healthy adults, obtaining a mean of $102 \mathrm{cmH}_{2} \mathrm{O}$. These values are higher than the mean obtained in our study with healthy children and adolescents, with a mean value of $87.10 \mathrm{cmH}_{2} \mathrm{O}$. This can be explained, once muscle strength alters according to basal characteristics of age, sex and body mass index. 28 Furthermore, in the group of patients with asthma, we obtained a mean value even lower than healthy children and adults, with a mean of $78.27 \mathrm{cmH}_{2} \mathrm{O}$, which suggests that besides age, pulmonary conditions such as asthma can reduce the values of dynamic muscle strength.

Besides, in a cross-sectional study carried out with students in the year 2013, it was observed a negative correlation between MIP and BMI, which can explain values lower than the predicted in our population, in which $35.0 \%$ of our sample were classified as overweight or obse. 26

In our study, the MIP values were higher than SIndex in asthmatic children and adolescents, corroborating with the findings of Minahan et al.16 in an adult population. The lower S-Index values could be related to the number of repetitions proposed for the analysis: because of they are children, ten repetitions may not be sufficient to find the maximum S-Index value due to the learning effect in the evaluation maneuver. More studies are necessary for a definition in children and adolescents. 27

It was yet observed, in our study, that the higher the height, the higher the S-Index in the asthmatic population. On the other hand, the study of Murphy and Wilson, ${ }^{23}$ height was proven being a negative predictor for women only, however, these data cannot be compared to each other, for the evaluation methods and population are different. In regards of the MEP evaluation, our finding are discrepant in relation to the aforementioned author, once it was evidenced a significant difference between the means of compared cases to the predicted values for the population. ${ }^{29}$ A possible explanation for the decrease of MEP in asthmatic people may be related to the physiopathology of the disease, due to the obstruction of air flux and the increase of resistance of the air tract, mainly in expiration, hindering the liberation of flux and reducing the expected values. ${ }^{7}$

Expiration in physiological conditions is a passive maneuver, which occurs only by the lung's elastic recoil. In conditions of maximum and submaximal effort (during the evaluation maneuver), the activation of accessory expiratory muscles (abdominal) increases MEP values. ${ }^{29}$ In asthmatic children, it is observed biomechanical disadvantage generated by the resistance of augmented respiratory tract, resulting in low activation of muscles during maximum efforts. Such factors can explain the lower values of MEP in the asthmatic group of our study. 7,29

Another important factor is the use of corticosteroids in medical treatment of asthma. It was observed that $50 \%$ of asthmatic children and adolescents included in the study used medium to high daily doses of inhaled corticoid, and there is evidence that its prolonged use can lead to muscle weakness due to the myopathy induced by steroids. 12 In addition to these factors, the MEP values have high indexes of false positive for expiratory weakness, once low values can be caused by submaximal efforts or leaking from the mouthpiece's edge. 14

In our study, these risks were reduced, by the trustworthy control of these variables, by means of visual feedback and verbal stimulation so that they feel motivated to use their maximum strength, and always oriented to maintain their lips sealed in order to avoid leaking.

The present study demonstrated that static inspiratory muscle strength (MIP) of asthmatic children and adolescents does not differ compared to values predicted in literature, however, when exposed to dynamic assessment (S-Index), the latter presents higher values in healthy controls. Besides, S-Index demonstrated a positive correlation with children's height.

\section{Author's contribution}

Cordeiro JA, Silva CP: conception and planning of the work. Britto MCA: planning of the work. Andrade LB: conception and planning of the work, approval of the final version. 


\section{References}

1. Victor J, Silva E, Elle S, Ferreira A, Rodrigues A. Perfil da morbidade hospitalar por doenças respiratórias na infância de 0 a 9 anos na cidade de Maceió - AL no período de 2010 a 2014. Ciênc Biol Saúde. 2016; 3 (3): 43-58.

2. Nordlund B, Melén E, Schultz ES, Grönlund H, Hedlin G, Kull I. Prevalence of severe childhood asthma according to the WHO. Respir Med. 2014; 108 (8): 1234-7.

3. Kuschnir F, Gurgel R, Solé D, Costa E, Felix M, De Oliveira C, Vasconcellos M, Kuschnir M. ERICA: Prevalence of asthma in Brazilian adolescents. Rev Saúde Pública. 2016; 50 (Suppl. 1): 1-10.

4. Sociedade Brasileira de Pneumologia e Tisiologia. Diretrizes da Sociedade Brasileira de Pneumologia e Tisiologia para o Manejo da Asma - 2012. J Bras Pneumol. 2012; 38 (Supl.1): 1-46.

5. Cardoso T de A, Roncada C, Silva E, Pinto L, Jones MH, Stein RT, Pitrez PM. The impact of asthma in Brazil: a longitudinal analysis of data from a Brazilian national database system. J Bras Pneumol. 2017; 43 (3): 163-8.

6. Asher I, Pearce N. Global burden of asthma among children. Int J Tuberc Lung Dis. 2014; 18 (11): 1269-78.

7. Mergoni M, Rossi A. Physiopathology of acute respiratory failure in COPD and asthma. Minerva Anestesiol. 2001; 67 (4): 198-205.

8. Heinzmann-Filho JP, Vendrusculo FM, Woszezenki CT, Piva TC, Santos AN, Barcellos AB, Vagliatti BB, Corrêa DG, Marttiello R, Donadio MV. Inspiratory muscle function in asthmatic and healthy subjects: influence of age, nutrition and physical activity. J Asthma. 2016; 53 (9): 893-9.

9. Shei R-J, Paris H, Wilhite D, Chapman R, Mickleborough $\mathrm{T}$. The role of inspiratory muscle training in the management of asthma and exercise-induced bronchoconstriction. Phys Sportsmed. 2016; 44 (4): 327-34.

10. Ramos E, de Oliveira LV, Silva A, Costa I, Corrêa JC, Costa D, Alves V, Donner C, Stirbulov R,Arena R, Sampaio LM. Peripheral muscle strength and functional capacity in patients with moderate to severe asthma. Multidiscip Respir Med. 2015; 10 (1): 3 .

11. Marcelino A, da Cunha D, da Cunha R, da Silva $H$ Respiratory muscle strength in asthmatic children. Int Arch Otorhinolaryngol. 2013; 16 (4): 492-6.

12. Akkoca O, Mungan D. Inhaled and systemic corticosteroid therapies : do they contribute to inspiratory muscle weakness in asthma? Respiration. 1999; 66: 332-7.

13. Neumannová K, Kováčiková Z, Zatloukal J, Elfmark M, Rydlová J, Janura M. Respiratory muscle strength in children with mild bronchial asthma disease. Acta Gymnica. 2017; 47 (4): 180-6.

14. Caruso P, Albuquerque A, Santana P, Cardenas L. Métodos diagnósticos para avaliação da força muscular inspiratória expiratória. J Bras Pneumol. 2015; 41 (2): 110-23.

\section{Received on October 25, 2019}

Final version presented on August 4, 2020

Approved on September 1, 2020
15. Marcelino A, Silva H. Role of maximal inspiratory presure in the evaluetion of respiratory muscle strength in asthmatics - Systematic review. Rev Port Pneumol. 2010; 16 (3): 463-70.

16. Minahan C, Sheehan B, Doutreband R, Kirkwood T, Reeves D. Repeated-Sprint Cycling Does Not Induce Respiratory Muscle Fatigue in Active Adults : Measurements from The Powerbreathe ${ }^{\circledR}$ Inspiratory Muscle Trainer. J Sport Sci Med. 2015; 14: 233-8

17. Chiappa GR, Roncada C. Avaliação da função muscular ventilatória. 2016; (April)

18. Global Initiative for Asthma. Pocket Guide for Asthma Management and Prevention; 2018. Disponível em: www.ginasthma.com

19. Santuz P, Baraldi E, Zaramella P, Filippone M, Zacchello F Factors limiting exercise performance in long-term survivors of bronchopulmonary dysplasia. Am J RespirCritCare Med. 1995; 152: 1284-9.

20. Cálculo do Índice de Massa Corporal (IMC) infantil. [acesso em 23 Fev 2018]. Disponível em: $<$ https://aps.bvs.br/apps/calculadoras/?page=7.

21. American Thoracic Society/European Respiratory Society. ATS/ERS Statement on respiratory muscle testing. Am J Respir Crit Care Med. 2002; 166 (15): 518-624.

22. Lanza FC, de Moraes Santos ML, Selman JPR, Silva JC, Marcolin N, Santos J, Oliveira CM.G, Lago PD, Corso SD. Reference equation for respiratory pressures in pediatric population: a multicenter study. PLoS ONE. 2015; 10 (8): 1-9.

23. Murphy AJ, Wilson GJ. Poor correlations between isometric tests and dynamic performance: relationship to muscle acti-vation. Eur J Appl Physiol Occup Physiol. 1996; 73 (34): 353-7.

24. Melzer E, Souhrada JF. Decrease of respiratory musclestrength and static lung volumes in obese asthmatics.Am Rev Respir Dis. 1980; 121 (1): 17-22.

25. Marks J, Pasterkamp H, Tal A, Leahy F. Relationship between respiratory muscle strength, nutritional status, and lung volume in cystic fibrosis and asthma. Am Rev Respir Dis. 1986 ; 133 (3): 414-7

26. Mckenzie DK, Gandevia SC. Strength and endurance of inspiratory, expiratory, and limb muscles in asthma. Am Rev Respir Dis. 1986; 134(5): 999-1004.

27. Silva PE, de Carvalho KL, Frazão M, Maldaner V, Daniel CR, Gomes-Neto M. Assessment of Maximum Dynamic Inspiratory Pressure. Respir Care. 2018; 63 (10): 1231-8.

28. Rosa, George Jung da e SCHIVINSKI, Camila Isabel S.Avaliação da força muscular respiratória de crianças segundo a classificação do índice de massa corporal.Rev Paul Pediatr. 2014, 32 (2): 250-5.

29. Weiner S, Suo J, Fernandez E, Cherniack RM. The effect of hyperinflation on respiratory muscle strength and efficiency in healthy subjects and patients with asthma. Am Rev Respir Dis. 1990; 141: 1501-5. 